\title{
Bifeprunox: a novel antipsychotic agent with partial agonist properties at dopamine D2 and serotonin $5-\mathrm{HT}_{1 \mathrm{~A}}$ receptors
}

\author{
Marie-Louise $G$ \\ Wadenberg \\ University of Kalmar, \\ Department of Natural \\ Sciences, Norra Vagen 49 , \\ SE-391 82 Kalmar, Sweden \\ Tel.: + 46480446277 ; \\ Fax: +46480446244 ; \\ marie-louise.wadenberg@ \\ bik.se
}

\begin{abstract}
Most second-generation, atypical, dopamine (DA) D2/5-HT2 blocking antipsychotics still induce extrapyramidal side effects (EPS) in higher doses. Weight gain and metabolic disturbances are also a problem, and negative and cognitive symptoms have not been sufficiently addressed. The current brain DA mesolimbic hyperactive/mesocortical hypoactive hypothesis of schizophrenia suggests that DA D2/5-HT ${ }_{1 A}$ receptor partial agonist properties may be more efficacious with less side effects. DA D2 receptor partial agonists may stabilize a hyperactive/hypoactive DA condition. Additional $5-\mathrm{HT}_{1 \mathrm{~A}}$ stimulation may enhance therapeutic efficacy and also improve EPS liability profile. In clinical trials in schizophrenic patients, the novel DA D2/5- $\mathrm{HT}_{1 \mathrm{~A}}$ partial agonist bifeprunox indeed demonstrates therapeutic efficacy, a safe EPS profile and appears beneficial regarding weight gain, prolactin, blood lipid and glucose levels and cardiac rhythm. The data on bifeprunox are promising and suggest that combined DA D2/5-HT 1 A partial agonism may well be important properties for future-generation antipsychotics.
\end{abstract}

Bifeprunox, a novel antipsychotic agent with a so-called third-generation atypical pharmacological profile, is currently in clinical trials and expected to launch as a schizophrenia therapy in the American market sometime in 2007, and in Europe in 2008. It is also being considered for treatment of bipolar disorder [101].

\section{Background}

Schizophrenia affects around $1 \%$ of the general population worldwide. The symptomatology includes positive symptoms (e.g., hallucinations, delusions and paranoia), negative symptoms (e.g., social withdrawal, poverty of speech, flat affect), as well as features of cognitive impairment. The main pharmacological property and therapeutic mechanism of action of traditional antipsychotic drugs (APDs), such as haloperidol $\left(\mathrm{Haldol}^{\circledR}\right)$, is dopamine (DA) D2 receptor blockade. However, owing to high DA D2 receptor occupancy in therapeutic doses, treatment with these drugs is frequently accompanied by disturbing extrapyramidal side effects (EPS), such as acute dystonia and parkinsonism, as well as endocrine effects such as increased prolactin levels. While effective against positive symptoms, these drugs have, over time, proven to be less efficacious against negative symptoms and cognitive impairment, and may even worsen these symptoms.

The antipsychotic clozapine (Leponex ${ }^{\circledR}$, Cloz$\left.\operatorname{aril}^{\circledR}\right)$, a dibenzodiazepine that was introduced in 1967 [1], on the other hand, is pharmacologically different, with a multireceptor affinity profile
(DA D1, D2, D4, 5- $\mathrm{HT}_{2 \mathrm{~A}} / \mathrm{C}, 5-\mathrm{HT}_{1 \mathrm{~A}}$, histamine $H 1, \alpha_{1}, \alpha_{2}$, cholinergic muscarinic receptor affinity) and comparatively lower affinity for the DA D2 receptor than traditional APDs. Clozapine produces good antipsychotic effect with virtually no EPS in therapeutic doses, and was therefore labeled atypical. Compared with traditional APDs, clozapine also shows superior therapeutic efficacy in treatment-resistant patients [2,3], beneficial effects against some aspects of cognitive impairment [4], and is superior to newer, atypical (second-generation) APDs, such as olanzapine, for preventing suicide amongst patients with schizophrenia and schizoaffective disorders [5]. This has created speculations in the drug development industry as to which pharmacological properties may primarily be responsible for its unique efficacy and atypicality profile. Clozapine is, however, associated with an increased risk for agranulocytosis, and was even temporarily withdrawn from the market due to a number of cases with fatal outcomes [6].

\section{Pathophysiology of schizophrenia}

The therapeutic efficacy of DA D2 receptor blocking traditional APDs suggested an overactivity of brain DA neural transmission in schizophrenia (the dopamine hypothesis of schizophrenia). However, while recent data more directly point to a specific mesolimbic/subcortical dopaminergic over-reactivity as responsible for the positive symptoms in schizophrenia [7], other data suggest that negative 
symptoms and cognitive disturbances may instead be due to a possibly parallel hypodopaminergic state in prefrontal brain areas [8]. This latter hypothesis is further supported by findings suggesting a dysregulation of the dopamine D1 receptor [9], known to be important for normal cognitive functions [10], and by findings indicating a hypofunction of the glutamatergic $N$-methyl-D-aspartate receptor [11] in schizophrenic individuals as assessed postmortem. Thus, current knowledge would suggest that it might be more appropriate to think of schizophrenia as a dual pathology disease.

\section{Antipsychotic drug development: overview of the market}

Based on the hypothesis of a combined low DA D2 and high $5-\mathrm{HT}_{2}$ receptor affinity ratio as an important mechanism of action of clozapine [12], the second-generation, so-called atypical APDs such as risperidone (Risperdal ${ }^{\circledR}$ ) [13] and olanzapine (Zyprexa ${ }^{\circledR}$ ) [14] were developed. These drugs are an improvement in schizophrenia therapy, and EPS liability is often reduced. This is most likely because additional $5-\mathrm{HT}_{2}$ receptor blockage may allow for sufficient therapeutic efficacy at lower doses with subsequent lower DA D2 receptor occupancy. Patients needing higher doses still show emerging EPS, presumably because of a subsequent increase in DA D2 receptor occupancy. Experimental data also support this notion [15-18].

$5-\mathrm{HT}_{2}$ receptor blockade, in combination with selective DA D2 receptor antagonists, has also been shown to increase prefrontal DA output as measured experimentally by in vivo microdialysis in rats [19]. Nevertheless, treatment-resistant patients, patients demonstrating suicidal behavior, or pronounced negative and/or cognitive symptoms still do not always respond optimally to treatment with the atypical APDs. Another serious concern with the atypicals, including clozapine, is their propensity to induce weight gain, as well as metabolic disturbances such as Type 2 diabetes, insulin resistance and dyslipidemia [20]. Both clozapine and olanzapine show high liability in this respect, while risperidone has a more beneficial profile. Affinity for the histamine $\mathrm{H} 1$ receptor has been shown to be significantly correlated to weight gain [21], but affinity for the $5-\mathrm{HT}_{2 \mathrm{C}}$ receptor subtype may also be a factor. Thus, in order to avoid such side effects, future APDs should preferably be devoid of histamine $\mathrm{H} 1$ receptor affinity.
AstraZeneca's atypical APD quetiapine (ICI 204,636; Seroquel $\left.{ }^{\circledR}\right)$, a dibenzothiazepine introduced in the mid-1990s, is also on the market. Quetiapine has a clozapine-like pharmacological profile, including low DA D2 receptor affinity and high 5-HT2, $\alpha_{1}$ and histamine $\mathrm{H} 1$ receptor affinity. Its therapeutic profile is similar to clozapine, with less EPS and prolactin elevation, but relatively high liability regarding weight gain, dyslipidemia, as well as a propensity to induce sedation, hypotension and, in some cases, syncope.

Recently, focus has been on agonism/partial agonism at the $5-\mathrm{HT}_{1 \mathrm{~A}}$ receptor [22]. Experimentally, $5-\mathrm{HT}_{1 \mathrm{~A}}$ receptor stimulation produces a preferential increase in prefrontal cortex DA release [23], an effect that is expected to be beneficial against negative and cognitive symptoms in schizophrenia. It is also possible that $5-\mathrm{HT}_{1 \mathrm{~A}}$ receptor agonism may contribute both to a general antipsychotic effect as well as a reduced EPS liability [24-26]. Indeed, 5- $\mathrm{HT}_{1 \mathrm{~A}}$ receptors have been reported by some to be upregulated in frontal cortex of schizophrenic individuals as determined postmortem [27]. Some clinical augmentation studies have reported amelioration of negative symptoms, and reduced incidence of EPS with adjunctive treatment, with the 5-HT $\mathrm{HA}_{1 \mathrm{~A}}$ partial agonists buspirone or tandospirone to haloperidol-treated schizophrenic individuals $[28,29]$. The fact that clozapine shows agonist properties at the $5-\mathrm{HT}_{1 \mathrm{~A}}$ receptor may thus contribute to some aspects of its superior therapeutic profile [30,31].

The novel APDs ziprasidone $\left(\right.$ Zeldox $^{\circledR}$, Geodon $^{\circledR}$ ) [32] and aripiprazole (Abilify ${ }^{\circledR}$ ) [33] include $5-\mathrm{HT}_{1 \mathrm{~A}}$ agonist, or partial agonist, properties.

Ziprasidone was approved by the US FDA in 2001 for the treatment of schizophrenia, and is available in intramuscular (for acute agitation/aggression in schizophrenia) and oral forms. Ziprasidone is an antagonist at DA D2 and $5-\mathrm{HT}_{2 \mathrm{~A}}$ receptors, the affinity for the 5-HT2 receptor being an order of magnitude greater than that for the DA D2 receptor. In addition, ziprasidone is an agonist at the $5-\mathrm{HT}_{1 \mathrm{~A}}$ receptor [34], and has less affinity than, for example, clozapine and olanzapine, for histamine $\mathrm{H} 1$ receptors. Specific improvement of cognitive functions in clinically nonresponsive patients [35], as well as efficacy against negative symptoms [36,37], by ziprasidone treatment have been reported. In a head-to-head comparison study with olanzapine, ziprasidone also showed less propensity for weight gain, as well as a more beneficial lipid profile than olanzapine [38]. 
Intramuscular ziprasidone in acutely agitated patients showed a faster onset of effect and superior tolerability compared with haloperidol [39]. The most frequent adverse events with ziprasidone appear to be dyspepsia, nausea, dizziness and somnolence [40], while ziprasidone appears to have low liability for acute EPS, as well as weight gain. However, prolonged QTc issues were of some concern with ziprasidone in the context of its introduction to the market. Ziprasidone is also now approved for acute treatment of mania associated with bipolar disorder (for product summary, see [103]).

Aripiprazole was approved by the FDA in 2002 for the treatment of schizophrenia and is available in tablets and oral solution. Aripiprazole has partial agonist properties at the $5-\mathrm{HT}_{1 \mathrm{~A}}$ receptor and is a less potent antagonist at the $5-\mathrm{HT}_{2 \mathrm{~A}}$ receptor, has moderate affinity for histamine receptors, but differs from ziprasidone in that it also has partial agonist properties at the DA D2 receptor. With its combined DA $\mathrm{D} 2 / 5-\mathrm{HT}_{1 \mathrm{~A}}$ receptor partial agonist properties, aripiprazole could be considered a close predecessor to bifeprunox. Aripiprazole appears to be effective in schizophrenia and schizoaffective disorder, improve aspects of cognitive functioning such as verbal skills, have few EPS adverse events and have a low propensity for weight gain or hyperprolactinemia [41].

In a head-to-head study with haloperidol, aripiprazole showed equal therapeutic efficacy, a better EPS liability profile and no prolactin elevation. There was no significant difference in body weight changes between the two drugs and placebo [42]. Adverse events for aripiprazole include headache, nausea, vomiting, somnolence, insomnia and akathisia. Cardiovascular effects, such as increased QTc interval, may be more of a concern with ziprasidone than with aripiprazole. Aripiprazole is also approved for acute treatment of mania in bipolar disorder (for product summary, see [103]).

Taken together, ziprasidone and aripiprazole show an advantage over other available APDs, primarily regarding EPS liability, prolactin levels, and propensity for weight gain and metabolic side effects. However, these drugs have only been on the market for a few years, and more data are needed to accurately assess whether they are indeed significantly superior to other available traditional, as well as second-generation, atypical APDs.

In addition, it is not clear to what extent 5-HT1A receptor agonism of these two novel APDs contributes to their pharmacologi- $\mathrm{cal} /$ therapeutical profile. Thus, based on preclinical behavioral and receptor occupancy data, it has been suggested that aripiprazole in clinically relevant doses mainly occupies DA D2 receptors, while significant 5-HT2 and $5-\mathrm{HT}_{1 \mathrm{~A}}$ receptor occupancy by aripiprazole occurs first at higher, not clinically relevant doses [43].

\section{Partial agonism at the D2 receptor \& the dual pathology hypothesis in schizophrenia}

It is becoming increasingly clear that the degree of cognitive impairment in schizophrenia is closely correlated to lifetime prognosis. Therefore, antipsychotic drug development research now focuses on drugs with cognitive enhancing properties. With the current notion that a dual DA brain chemical pathology underlies schizophrenia (see above), the ideal treatment could be a compound with normalizing/stabilizing properties. Hypothetically, that could possibly be accomplished with a partial DA D2 receptor agonist [44]. A partial agonist is a drug that, despite its affinity for a certain receptor, is not able to elicit a $100 \%$ tissue response, even at higher doses. By occupying a certain percentage of DA receptors, a partial agonist may act to prevent excessive stimulation in brain areas with hyperactive endogenous DA, while not causing DA transmission blockage in hypodopaminergic brain areas. Alternatively, partial agonists being selective for DA autoreceptors exerting negative feedback control on DA release/synthesis [45], may that way act as potential stabilizers of dopamine dysregulation. In addition, partial agonists should be less likely to cause side effects due to their adaptive pharmacodynamic property and subsequent flexibility.

The idea of using DA receptor partial agonists in the treatment of schizophrenia is not entirely new. A few DA partial agonists have already been tried, with moderate success [46-48]. In this context, aripiprazole and bifeprunox (along with a number of new drugs in development, such as SLV313, sarizotan and SSR 181507) represent a new class of DA partial agonists with a somewhat modified pharmacological profile.

\section{Introduction to bifeprunox Chemistry}

1-(2-oxo-benzoxazolin-7-yl)-4-(3-biphe-

nyl)methylpiperazinemesylate (generic name bifeprunox or DU127090), with molecular formula $\mathrm{C}_{24} \mathrm{H}_{23} \quad \mathrm{~N}_{3} \mathrm{O}_{2}$, and molecular weight 
481.5 (bifeprunox mesylate) and 385.5 (base; Figure 1), is a novel/third-generation antipsychotic in a series of 1-aryl-4-(biarylmethylene)piperazines developed by Solvay Pharma, with partial agonist properties at the DA D2 and (partial) agonist properties at 5-HT1A receptors.

\section{Pharmacodynamics}

Bifeprunox (DU127090) has high affinity (pKi 8.5) for DA D2 receptors. Its DA D2 receptor affinity is similar to haloperidol and risperidone, but higher than that of clozapine or olanzapine. It also has high affinity for human (h)D3 (pKi 9.1), and hD4 ( $\mathrm{pKi} 8.0$ ) receptors, and for 5- $\mathrm{HT}_{1 \mathrm{~A}}$ receptors (pKi 8.2) [49,50,51]. In addition, it is virtually devoid of affinity for $5-\mathrm{HT}_{2 \mathrm{~A} / \mathrm{C}}$ receptors (compared with aripiprazole), $\alpha_{1}$ and $\alpha_{2}$ adrenoceptors, cholinergic muscarinic or histaminergic receptors [49]. In assays using $\mathrm{hD} 2_{\mathrm{L}}$-expressing cell lines, bifeprunox showed high affinity, but low efficacy (intrinsic activity), at DA D2 receptors, consistent with partial agonism [49]. This was further confirmed in vivo using microdialysis in freely moving rats. By measuring the synthesis rate of both dopamine and serotonin in the presence of aromatic decarboxylase inhibition, bifeprunox dose-dependently, but incompletely, increased rat striatal L-3,4-dihydroxyphenylalanine accumulation, but decreased 5-HTP accumulation dose-dependently and maximally [52]. Compared with the DA D2 receptor antagonist haloperidol that maximally increases rat striatal L-3,4-dihydroxyphenylalanine accumulation, this would be indicative of partial agonism by bifeprunox at DA D2 receptors. Similarly, compared with the selective $5-\mathrm{HT}_{1 \mathrm{~A}}$ receptor agonist $8-\mathrm{OH}$-DPAT that produces a maximal decrease in 5-HTP accumulation, these data would indicate full agonism by bifeprunox at 5 -HT1A receptors regulating 5-HT synthesis.

\section{Figure 1. Molecular structure of bifeprunox.}

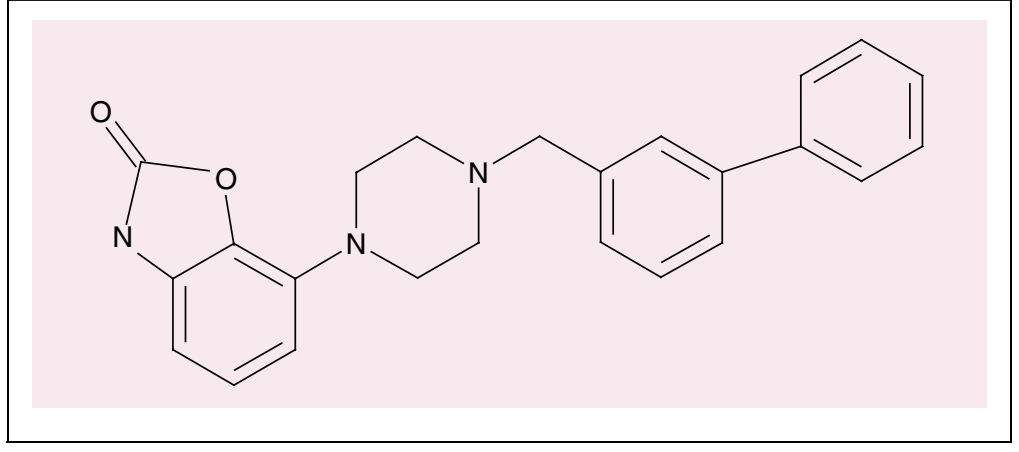

Partial agonism/agonism properties by bifeprunox at DA D2 and 5-HT1A receptors, respectively, has subsequently been confirmed in several experimental studies [51,53-55].

Recently, bifeprunox was compared with aripiprazole for effects on rat ventral tegmental area (VTA) dopamine and dorsal raphe serotonin neuronal activity, respectively [56]. Both bifeprunox $(50-400 \mu \mathrm{g} / \mathrm{kg}$ intravenous [IV]) and aripiprazole (200-500 $\mu \mathrm{g} / \mathrm{kg}$ IV) dose-dependently inhibited the firing rate and suppressed bursting activity of VTA DA cells. Similarly, both drugs significantly reversed the suppressing effect of VTA DA cell-firing activity by the full DA D2 receptor agonist apomorphine. Both drugs also dose-dependently inhibited the firing rate of dorsal raphe 5-HT cells, and this effect was prevented by treatment with the selective 5-HT1A receptor antagonist WAY-100635. Thus, bifeprunox (and aripiprazole), also behave as combined partial D2/5- $\mathrm{HT}_{1 \mathrm{~A}}$ receptor agonists in this experimental paradigm, although aripiprazole was in general somewhat less potent.

Taken together, a large body of data using different experimental paradigms consistently show that bifeprunox displays a profile of high affinity but low efficacy at the DA D2 receptor (consistent with a partial agonist profile), and lower affinity and moderately high efficacy at the $5-\mathrm{HT}_{1 \mathrm{~A}}$ receptor, indicative of a full agonist profile as shown in some, but not all, models.

Experimental behavioral data suggest that modulation of DA D4 receptors may improve cognitive functioning. Using functional assays at the human DA D4.4 receptor, it was recently confirmed that bifeprunox exhibits potent partial agonist properties at hD4.4 receptors. Aripiprazole also exhibited partial agonist properties at $\mathrm{hD} 4.4$ receptors but with lower potency, while typical and atypical APDs tested behaved as antagonists [57].

\section{Experimental data on bifeprunox}

In the conditioned avoidance response (CAR) test with high predictive validity for antipsychotic activity, bifeprunox showed antipsychotic-like activity in rats at doses as low as $0.25 \mathrm{mg} / \mathrm{kg}$, potently reversed psychotic-like hyperactivity behavior induced by phencyclidine (PCP) in mice, and also potently antagonized D-amphetamine $(0.5 \mathrm{mg} / \mathrm{kg})$ induced hyperlocomotion in rats, while having no effect on baseline activity by itself in this dose range [58,59]. In addition, bifeprunox did not produce any signs of catalepsy $(\mathrm{ED} 50>16 \mathrm{mg} / \mathrm{kg})$ indicating a safe EPS liability profile $[58,60]$. 
In vivo striatal DA D2 receptor occupancy by bifeprunox in rats has been reported to be more than $90 \%$ at $0.25 \mathrm{mg} / \mathrm{kg}$ (the minimum effective dose in the CAR test). The DA D2 occupancy of bifeprunox was long-lasting, presumably because of slow receptor off-rate rather than an accumulation of bifeprunox in the brain. Despite the high DA D2 receptor occupancy, no catalepsy was observed, even at high doses $(>16 \mathrm{mg} / \mathrm{kg})$, which most likely can be explained by the partial agonism at the DA D2 receptor in combination with the $5-\mathrm{HT}_{1 \mathrm{~A}}$ agonism of bifeprunox Table 1 [61].

In rats with unilateral lesions by 6-hydroxydopamine of dopaminergic input to the striatum, DA agonists cause contralateral turning due to stimulation of lesion-induced supersensitive receptors. Bifeprunox also causes contralateral turning in such animals $(\mathrm{ED} 50=0.026 \mathrm{mg} / \mathrm{kg})$, indicative of DA agonist properties of bifeprunox [62], while in the apomorphine-induced climbing test in mice, bifeprunox acted as a partial DA agonist by inhibiting this effect $(\mathrm{ED} 50=0.14 \mathrm{mg} / \mathrm{kg}$ orally) [66]; (ED50 $=0.5 \mathrm{mg} / \mathrm{kg}$ intraperitoneally) $[63,64]$.

Further indications of a safe EPS liability profile of bifeprunox comes from studies in Cebus monkeys previously sensitized to neuroleptics. Thus, bifeprunox $(0.125-50 \mathrm{mg} / \mathrm{kg}$ orally) produced only mild dystonia and parkinsonian symptoms in these monkeys. Furthermore, these symptoms came to a plateau at a low dose and, in contrast to for example haloperidol, decreased with higher doses [65]. In this study, bifeprunox also had positive effects in these animals on reactivity and alertness to the environment, suggesting socially enhancing properties that may be beneficial against negative symptoms and cognitive impairment in schizophrenia.

Data from recent studies strongly suggest that the $5-\mathrm{HT}_{1 \mathrm{~A}}$ agonistic property of bifeprunox contributes to its favorable EPS profile. Thus, using the catalepsy bar test bifeprunox, at least up to $10 \mathrm{mg} / \mathrm{kg}$, did not produce catalepsy in mice. Aripiprazole, by comparison, produced little or no catalepsy up to $40 \mathrm{mg} / \mathrm{kg}$ in the same study. However, in the presence of the selective $5-\mathrm{HT}_{1 \mathrm{~A}}$ receptor antagonist WAY 100635 $(2.5 \mathrm{mg} / \mathrm{kg})$, bifeprunox produced significant catalepsy in the mice already at doses around $0.1 \mathrm{mg} / \mathrm{kg}$. For aripiprazole, an upward shift in dose-esponse was seen in the presence of WAY 100635 [66]. This was also seen in rats where bifeprunox, while not producing any catalepsy by itself, in the presence of WAY 100635 $(0.63 \mathrm{mg} / \mathrm{kg})$ produced significant catalepsy above $5 \mathrm{mg} / \mathrm{kg}$. In addition, bifeprunox $(0.1-10 \mathrm{mg} / \mathrm{kg})$ alone reversed haloperidol $(2.5 \mathrm{mg} / \mathrm{kg})$ induced catalepsy [67].

In behavioral models for cognitive disturbances and negative symptoms in schizophrenia, bifeprunox $(0.04-2.5 \mathrm{mg} / \mathrm{kg})$ reversed apomorphine-induced sensorimotor gating deficits (disruption of prepulse inhibition [PPI]), as did aripiprazole (at doses of 0.04 or $10 \mathrm{mg} / \mathrm{kg}$, but not in doses between those two) [68]. Contrary to aripiprazole, which reversed social interaction deficits induced by PCP in rats (at 0.04 or $0.16 \mathrm{mg} / \mathrm{kg})$, bifeprunox $(0.01-0.63 \mathrm{mg} / \mathrm{kg})$ failed to do so [69]. However, in a recent study both bifeprunox $(0.16 \mathrm{mg} / \mathrm{kg})$ and aripiprazole $(0.16 \mathrm{mg} / \mathrm{kg})$ reversed PCP-induced deficits in working, as well as reference, memory in rats. Bifeprunox had minimal (detrimental) effects by itself, while aripiprazole, according to the authors, showed more detrimental effects of its own [70].

Finally, bifeprunox has also demonstrated antidepressant, as well as anxiolytic, effects experimentally in rats $[60,71]$.

In summary, experimentally, bifeprunox produces antipsychotic-like effects in several animal models for antipsychotic activity, has little or no propensity to induce EPS, and appears to have efficacy in some animal models of cognitive disturbance. Bifeprunox also shows antidepressant/anxiolytic effects in animal behavioral models.

\section{Pharmacokinetics}

Available data on the pharmacokinetics of bifeprunox are incomplete. Thus, there are currently no published data available on the absorption, distribution and metabolism/elimination properties of bifeprunox.

In a study evaluating methods to determine the protein binding of bifeprunox in one plasma sample, it is stated that bifeprunox is an apolar basic compound with relatively high protein binding. Plasma concentrations are in the lower $\mathrm{ng} / \mathrm{ml}$ range [72]. A pharmacokinetic/pharmacodynamic model based on the preclinical data on bifeprunox obtained in the CAR test and the in vivo DA D2 occupancy data (see above), suggests that a clinically effective steady-state plasma concentration of bifeprunox would be around 5-10 $\mathrm{ng} / \mathrm{ml}$ [61]. In a study using the positron emission tomography technique, the correlation between DA D2 occupancy, dose and plasma concentration of bifeprunox was investigated in six healthy human male subjects. The DA D2 
Table 1. Effects of bifeprunox compared with aripiprazole on CAR (MED)/D2 occupancy (\%), and threshold for catalepsy.

\begin{tabular}{llll} 
Drug & CAR (MED $\mathbf{~ m g / k g , ~ s c )}$ & D2 occupancy (\%) & Catalepsy (ED50 $\mathbf{~ m g / k g , ~ s c ) ~}$ \\
Bifeprunox & 0.25 & $>90$ & $>16$ \\
Aripiprazole & 2.5 & $>90$ & $>20$ \\
\hline
\end{tabular}

MED: Minimum effective dose; sc: Subcutaneous.

Adapted from [61].

occupancy in these subjects was dose-related, with a 90\% DA D2 occupancy observed at bifeprunox greater than $10 \mathrm{mg}$. A higher dose (20 mg) did not further increase DA D2 occupancy, suggesting a plateau in DA D2 occupancy at $10 \mathrm{mg}$. Thus, bifeprunox would be expected to show antipsychotic effect at doses producing $90 \%$ D2 occupancy (i.e., doses $\geq 10 \mathrm{mg}$ ). Plasma half-life was reported to be $9 \mathrm{~h}$, but DA D2 occupancy $24 \mathrm{~h}$ after administration was still at $79 \%$. Contrary to most antipsychotics, prolactin levels actually decreased $(2.5 \%$ of baseline at $10 \mathrm{mg}$ ). There were no clinically relevant changes in ECG or vital signs measures [73-75].

\section{Clinical efficacy: completed \& ongoing clinical trials}

Bifeprunox is currently the lead compound of four of Solvay's new investigational antipsychotic drugs, which all have a similar pharmacological profile. The other drugs are SLV-310, SLV-313 and SLV-314. If successful in clinical trials, it will be marketed worldwide by Lundbeck A/S and by Solvay Pharmaceuticals and Wyeth in the USA, Canada, Mexico and Japan.

In a placebo-controlled Phase II trial in schizophrenic patients to assess an appropriate dose range, bifeprunox showed therapeutic efficacy and was also well tolerated. The incidence of EPS was similar to placebo. In addition, bifeprunox showed little propensity to produce weight gain, did not increase prolactin levels, had no adverse effects on blood lipids or glucose levels, and did not show QTc prolongation [104].

Based on these promising findings, a larger European Phase III trial was initiated in September 2003 by Solvay and Lundbeck A/S [101,105]. The launch in the European market was initially set to 2007. However, in January 2006, H Lundbeck $\mathrm{A} / \mathrm{S}$ announced that the review of clinical data regarding bifeprunox has led to a delayed submission of a registration dossier in the European Union, to 2008, "depending on the completion of additional Phase III comparative clinical work" [101].
In the USA, a Phase II trial was initiated in January 2006. This is a randomized, double-blind, placebo-controlled study to assess the tolerability/efficacy of bifeprunox in schizophrenic, schizoaffective or bipolar patients. The study is set for 2 months, with an optional 26-week open-label extension, with the aim of achieving the 'shortest tolerated titration dosing' to a dose of $40 \mathrm{mg} /$ day. In June 2006, Wyeth was reported to be planning to file an FDA approval and commercial launch of bifeprunox for the treatment of schizophrenia sometime in 2007 [101]. An NDA was submitted to FDA in October 2006 by Solvay [101; J Arnt, Personal Communication].

At the American College of Neuropsychopharmacology meeting in December 2006, additional data from completed clinical trials with bifeprunox became available. In a 6-week, randomized, double-blind, placebo-controlled study, using risperidone $(6 \mathrm{mg} /$ day $)$ as an active reference, bifeprunox (30 or $40 \mathrm{mg} /$ day) was evaluated against placebo in schizophrenic patients experiencing acute exacerbations. Safety and tolerability of bifeprunox was also evaluated. The total number of subjects was 599, the study was run in 38 centers and $40 \%$ of subjects completed the study. Primary outcome measure was change in Positive and Negative Symptom Scale (PANSS) total score (baseline to end point), using last observation carried forward (LOCF). In addition, EPS, weight gain, lipid profile and serum prolactin were monitored. Bifeprunox $30 \mathrm{mg}$, but not $40 \mathrm{mg}$, was superior to placebo in reduction of total PANSS score. This was also true for risperidone (6 mg). Most common adverse events with bifeprunox (30 or $40 \mathrm{mg}$ ) were gastrointestinally (GI)-related (e.g., constipation, nausea, vomiting, anorexia, dyspepsia). EPS signs in patients on bifeprunox were lower than with risperidone treatment. Bifeprunox also caused significant weight loss compared with placebo, while patients on risperidone experienced weight gain. There was also a significant (vs placebo) decrease in plasma prolactin levels in patients on bifeprunox, as well as a decrease in nonfasting plasma glucose, total serum cholesterol and triglycerides [76]. 
Furthermore, in a 6-week, randomized, double-blind, placebo-controlled study, again using risperidone $(6 \mathrm{mg} /$ day $)$ as an active reference, bifeprunox (5, 10 or $20 \mathrm{mg} /$ day) was evaluated in a dose-finding study against placebo in schizophrenic patients experiencing acute exacerbations. EPS, weight gain, lipid profile and serum prolactin were also monitored. The total number of subjects were 589 (18-65 years old), the study involved 37 centers, and $44 \%$ of subjects completed the study. Withdrawal from study due to lack of efficacy was $15 \%$ (bifeprunox $20 \mathrm{mg}$ ) versus $7 \%$ (risperidone $6 \mathrm{mg}$ ). The primary outcome measure was change in PANSS total score (baseline to end point) using LOCF. Bifeprunox $(20 \mathrm{mg})$ showed significant reduction of PANSS total score (vs placebo). Risperidone was also effective. EPS signs were similar to placebo. All doses of bifeprunox caused significant weight loss, as well as significant decrease in nonfasting cholesterol and triglyceride levels. Serum prolactin was also significantly (vs placebo) decreased, and no changes in ECG profile were observed [77].

A third 6-week, randomized, double-blind, placebo-controlled, parallel-group efficacy and safety study in schizophrenic patients (604 patients, in 32 centers) with acute exacerbations using bifeprunox (20 or 30 ), and with olanzapine $(15 \mathrm{mg} /$ day $)$ as an active reference, also showed a reduction by bifeprunox in PANSS total score (baseline to end point) using LOCF. However, the effect of bifeprunox in this trial did not reach statistical significance (vs placebo). Olanzapine showed significant therapeutic effect (vs placebo). Safety data indicated that bifeprunox was safe and well tolerated, as well as being associated with a beneficial metabolic profile (vs placebo). The completion rate was 48 and $47 \%$, for bifeprunox 20 and $30 \mathrm{mg}$, respectively [78].

Data on long-term efficacy and safety of bifeprunox were also presented. The study was a 6-month, randomized, double-blind, parallel-group, placebo-controlled trial in patients with stable schizophrenia ( $\geq 2$ years) with fixed doses $(20$ or $30 \mathrm{mg}$ ) of bifeprunox. A total of 497 subjects in 35 centers (six countries) were recruited, out of which $36.5 \%$ (biferunox $20 \mathrm{mg}$ ) and $32.6 \%$ (biferunox $30 \mathrm{mg}$ ) completed the study. The primary end point was time from randomization to deterioration. Metabolic syndrome parameters were measured in a subset of patients. Patients on bifeprunox (20 or $30 \mathrm{mg}$ ) showed significantly longer time to deterioration (vs placebo) with LOCF. In the placebo arm, there were in general more patients showing deterioration and also a shorter time to deterioration, compared with the bifeprunox arm. Bifeprunox also showed significant advantage (over placebo) for changes in PANSS total score. Both doses of bifeprunox were safe and well tolerated with a beneficial side-effect profile. Patients on bifeprunox also showed improved individual records on metabolic parameters - in particular regarding weight and lipids [79].

A study with preferential focus on the metabolic profile of bifeprunox was also presented. The study was based on integrated safety analyses from four 6 -week, double-blind trials and one 6-month, randomized, double-blind trial. A total of 1995 subjects from the 6-week trials, and 497 from the 6-month trial, were included. The study concludes that pooled data of metabolic results from these trials suggest that treatment with bifeprunox is associated with a reduced risk of metabolic complications such as weight gain, dyslipidemia and glucose dysregulation [80].

A summary of clinical data is presented in Table 2, [105]. Further clinical trials planned for bifeprunox are listed in Table 3 .

Bifeprunox was also earlier considered for the treatment of Parkinson's disease (PD). Clinical trials in Europe for PD have been mentioned in an earlier review on bifeprunox [81]. However, there is currently no reliable information available on the status of bifeprunox in this respect. In the primate 1-methyl-4-phenyl-1,2,3,6-tetrahydropyridine (MPTP) model of PD, however, bifeprunox $(1 \mathrm{mg} / \mathrm{kg})$ reversed MPTP-induced hypomotility and disability. The effect of bifeprunox was proportional to its intrinsic activity at DA D2 receptors and, according to the investigators, suggestive of antiparkinsonian effects [82].

\section{Safety \& tolerability}

In clinical trials, bifeprunox $(20,30$ or $40 \mathrm{mg}$ ) has been reported to be well tolerated, with no clinically relevant changes in electrocardiogram profile or vital signs measures. Bifeprunox also displays a safe EPS liability profile. Incidence of EPS was in general similar to placebo. Prolactin levels following bifeprunox treatment were reported to decrease rather than the opposite. Compared with earlier atypical APDs, bifeprunox appears to have a safer liability profile regarding weight gain and markers for metabolic syndrome. Thus, bifeprunox did not produce weight gain, and had no adverse effects on blood lipids or glucose levels in clinical trials completed at this point in time. Most common adverse events with bifeprunox were GI-related (e.g., constipation, nausea, 


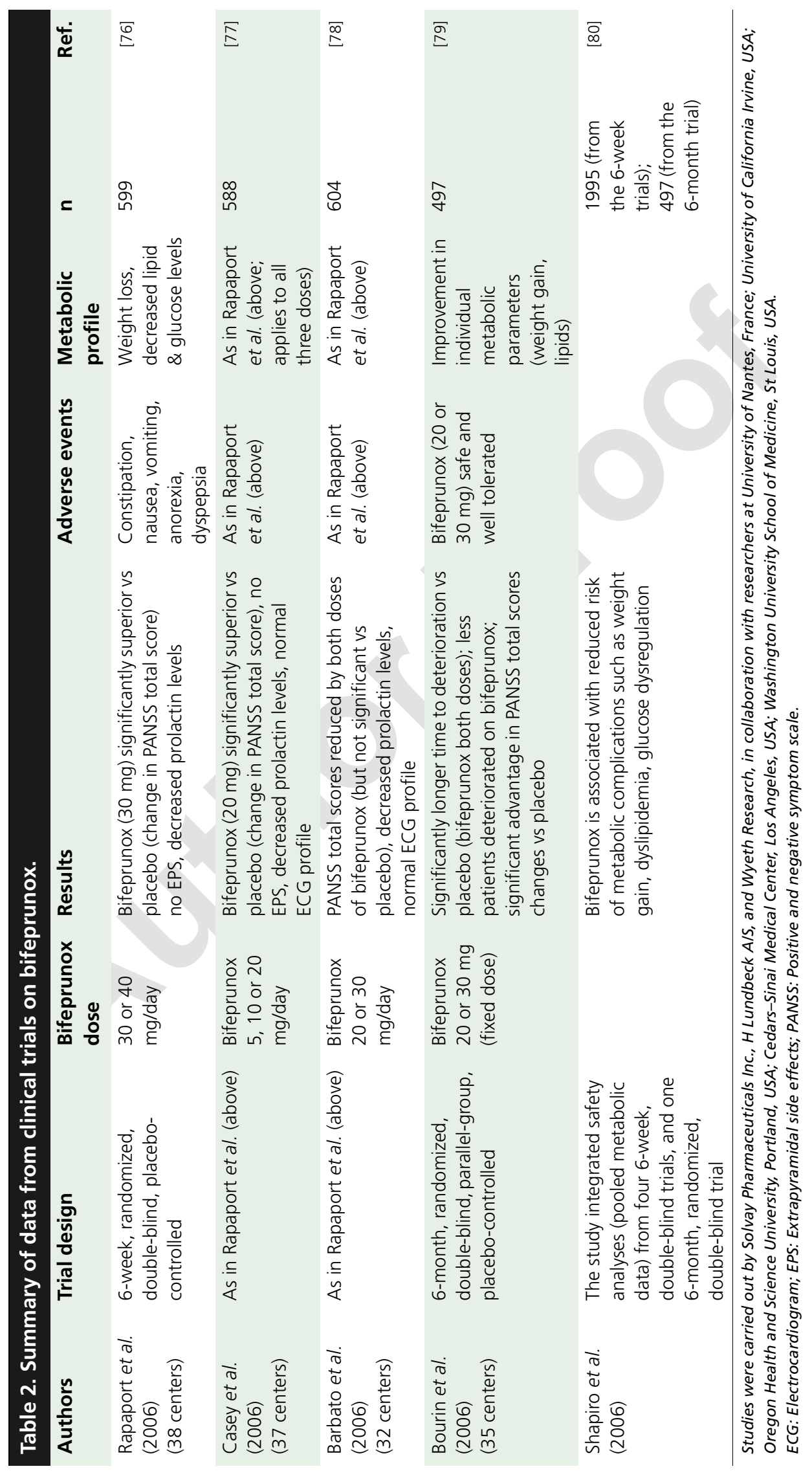




\section{Table 3. Clinical trials currently planned for bifeprunox.}

\begin{tabular}{lc} 
Trial & Status \\
Switch study of existing atypical antipsychotics to bifeprunox & Not yet recruiting \\
Progressively decreasing titration schedules of bifeprunox in subjects with schizophrenia or bipolar disorder & Recruiting \\
$\begin{array}{l}\text { Open-label extension study of bifeprunox in schizophrenia } \\
\text { Study evaluating bifeprunox in patients with schizophrenia }\end{array}$ & Not yet recruiting \\
$\begin{array}{l}\text { Study comparing bifeprunox with risperidone in the treatment of outpatients with schizophrenia:weight gain } \\
\text { being the primary end point }\end{array}$ & Not yet recruiting \\
$\begin{array}{l}\text { Treatment of elderly subjects with psychosis and behavioral disturbances associated with dementia of the } \\
\text { Alzheimer's type }\end{array}$ & Recruiting \\
\hline
\end{tabular}

Taken from [102].

vomiting, anorexia and dyspepsia). These events did not display dose-dependence in the 6-week trials, but showed a more dose-dependent profile, with an incidence of 5\% in the 6-month trial.

\section{Regulatory affairs}

Bifeprunox is not yet approved for use in any country.

\section{Conclusion}

Preclinical and clinical studies suggest that APDs with combined DA D2/5-HT1A partial agonist properties, such as aripiprazole and bifeprunox, may have an advantage over second-generation, mainly DA D2/5- $\mathrm{HT}_{2}$ receptor blocking, atypical APDs. Thus, bifeprunox displays antipsychotic-like effects in animal models for antipsychotic activity, a safe EPS liability profile, activity in some models of cognitive disturbance and antidepressant/anxiolytic-like effects in animal behavioral models.

In clinical trials in schizophrenic patients, bifeprunox (20 or $30 \mathrm{mg}$ ) showed significant therapeutic efficacy compared with placebo as measured by changes in PANSS total score as primary outcome measure and was well tolerated with most common adverse events being GI-related. The EPS profile was similar to placebo. Contrary to second-generation atypical antipsychotics, bifeprunox did not produce weight gain, and had no adverse effects on blood lipids or glucose levels. In addition, bifeprunox did not increase prolactin levels. There were also no adverse effects on cardiac rythm.

In summary, data on bifeprunox are consistent with what could be anticipated from a compound with combined DA D2/5- $\mathrm{HT}_{1 \mathrm{~A}}$ partial agonist properties. Clinical data on bifeprunox so far indicate that bifeprunox compares favorably with aripiprazole on safety and tolerability markers such as EPS liability, effects on prolactin levels and QTc interval. Contrary to second-generation atypical APDs, bifeprunox shows a beneficial profile regarding weight gain and markers for metabolic syndrome that are also similar to aripiprazole. Clinical data on antipsychotic efficacy of bifeprunox also appear promising. However, currently most clinical data are available only as preliminary reports presented as abstracts at scientific meetings. Needless to say, peer-reviewed articles would provide a clearer picture of the status of bifeprunox as an antipsychotic. Further (Phase II-III) studies directly designed to compare the clinical efficacy of bifeprunox with that of second-generation atypical APDs, as well as with aripiprazole, remain to be performed/published, before it is possible to assess the full therapeutic efficacy profile of bifeprunox in schizophrenia. In addition, information on pharmacokinetic properties of bifeprunox is still not available.

\section{Future perspective}

Atypical APDs such as clozapine, risperidone and olanzapine act on several target sites. In addition, their mechanism of action is often that of an antagonist, thereby limiting their pharmacological flexibility/adaptability. Most atypicals still also come with some serious adverse events such as induction of agranulocytosis, weight gain, metabolic syndrome and cardiovascular effects. Furthermore, therapeutic response/efficacy varies and is often far from optimal. Partial DA D2/5- $\mathrm{HT}_{1 \mathrm{~A}}$ agonists like aripiprazole and bifeprunox represent a new class (third-generation) of APDs, that are moving away from the multireceptor, mainly antagonistic affinity profile represented by, for example, clozapine and olanzapine. Given the current notion of a dual pathology in schizophrenia (as outlined above), partial DA D2 agonists, with or without additional 5-HT1A 


\section{Executive summary}

\section{Mechanisms of action}

- Bifeprunox is a partial agonist at the dopamine D2 receptor and a (partial) agonist at serotonin (5-HT) ${ }_{1 \mathrm{~A}}$ receptors.

- As partial agonists, by virtue of their definition, are flexible/adaptive to brain tissue/neurotransmitter conditions, these properties in combination are expected to optimize overall therapeutic response in schizophrenic individuals, and at the same time minimize the risk of side effects.

\section{Pharmacokinetic properties}

- Available data on the pharmacokinetics of bifeprunox are incomplete.

- Bifeprunox is an apolar basic compound with relatively high protein binding.

- Plasma concentrations are in the lower $\mathrm{ng} / \mathrm{ml}$ range.

- A pharmacokinetic/pharmacodynamic modeling of preclinical data on bifeprunox suggests that a clinically effective steady-state plasma concentration of bifeprunox would be around 5-10 ng/ml.

- Plasma half-life is $9 \mathrm{~h}$.

\section{Clinical efficacy}

- A positron emission tomography study showed that D2 occupancy in six healthy human male subjects was dose-related with a $90 \%$ D2 occupancy observed at bifeprunox greater than or equal to $10 \mathrm{mg}$.

- The D2 occupancy $24 \mathrm{~h}$ after administration was still fairly high (79\%).

- Bifeprunox would be expected to show antipsychotic effects in the clinic starting at doses producing $90 \%$ D2 occupancy (i.e., $\geq 10 \mathrm{mg}$ ).

- In a placebo-controlled Phase II trial in schizophrenic patients to assess an appropriate dose range, bifeprunox showed therapeutic efficacy.

- Further data on clinical efficacy of bifeprunox were recently made available from three 6-week, randomized, double-blind, placebo-controlled trials, together involving a total of 1792 schizophrenic individuals experiencing acute exacerbation. Two of these studies demonstrated statistically significant therapeutic efficacy (change in Positive And Negative Symptom Scale [PANSS] total score) versus placebo by bifeprunox 20 or $30 \mathrm{mg} /$ day. The third trial showed a reduction in PANSS total score by bifeprunox (20 or $30 \mathrm{mg}$ ) versus placebo that, however, did not reach statistical significance.

- A 6-month randomized, double-blind, parallel-group, placebo-controlled trial with a total of 497 patients with stable schizophrenia demonstrated that bifeprunox $(20$ or $30 \mathrm{mg}$ ) significantly prolonged time to deterioration compared with placebo. Bifeprunox also showed significant advantage (over placebo) for changes in PANSS total score, and more patients in the placebo arm showed deterioration compared with patients in the bifeprunox arm.

\section{Safety \& tolerability}

- Bifeprunox was shown to be well tolerated.

- Most common adverse events with bifeprunox (30 or 40 mg) were gastrointestinal-related (e.g., constipation, nausea, vomiting, anorexia and dyspepsia).

- The incidence of extrapyramidal side effects was similar to placebo.

- Bifeprunox showed little propensity to produce weight gain.

- Bifeprunox did not increase prolactin levels.

- Bifeprunox had no adverse effects on blood lipids or glucose levels.

- Bifeprunox did not show QTc prolongation.

\section{Drug interaction}

- Information on drug interactions are not yet available.

\section{Dosage \& administration}

- Dosage of bifeprunox is expected to be in the range of 20 to $30 \mathrm{mg}$

- Formulation is expected to be in the form of tablets.

(partial) agonistic properties, may well, by virtue of their DA stabilizing properties, prove to be more efficacious and have a significantly reduced side effect liability profile, in particular with additional $5-\mathrm{HT}_{1 \mathrm{~A}}$ agonism.

The work to fine-tune future APDs will, among other things, most likely include the challenge to find out just the right DA D2/5- $\mathrm{HT}_{1 \mathrm{~A}}$ affinity and efficacy balance for optimal therapeutic effect/fewer side effects. Along another line, further research on the molecular basis behind the brain pathology in schizophrenia may hold important answers that are sure to be helpful in optimizing the design of novel antipsychotic molecules. In that context, the idea of compounds with tissue sensitive, brain chemical stabilizing properties appears to be a promising lead.

\section{Acknowledgements}

I would like to thank Drs Jorn Arnt, Peter Hertel and Rolf Feenstra for valuable information via personal communication. 


\section{Bibliography}

Papers of special note have been highlighted as either of interest $(\bullet)$ or of considerable interest $(\bullet \bullet)$ to readers.

1. Hunziker F, Fisher E, Schmutz J: 1 1-Amino5H-dibenzo(b,e)-1,4-diazepine-10.

Mitteilungen über siebengliedrige

Heterocyclen. Helv. Chim. Acta. 50, 1588

(1967).

2. Kane JM, Honigfeld G, Singer J, Meltzer H: Clozapine in treatment-resistant schizophrenics. Psychopharmacol. Bull. 24, 62-67 (1988).

3. Kane JM, Marder SR, Schooler NR et al.: Clozapine and haloperidol in moderately refractory schizophrenia: a 6-month randomized and double-blind comparison. Arch. Gen. Psychiatry 58, 965-972 (2001).

4. Meltzer HY, McGurk SR: The effects of clozapine, risperidone, and olanzapine on cognitive function in schizophrenia. Schizophr. Bull. 25, 233-255 (1999).

5. Meltzer HY, Alphs L, Green AI et al: Clozapine treatment for suicidality in schizophrenia: International Suicide Prevention Trial (InterSePT). Arch. Gen. Psychiatry 60(1), 82-91 (2003).

6. Levinson DF, Simpson G: Serious nonextrapyramidal adverse effects of neuroleptics: sudden death, agranulocytosis, and hepatotoxicity. In: Psychopharmacology: the third generation of progress. Meltzer $\mathrm{H}$ (Ed.). Raven Press, NY, USA, 1431-1436 (1987).

7. Laruelle M, Abi-Dargham A, van Dyck CH et al: Single photon emission computerized tomography imaging of amphetamineinduced dopamine release in drug-free schizophrenic subjects. Proc. Natl Acad. Sci. USA 93, 9235-9240 (1996).

8. Weinberger DR, Egan MF, Bertolino A et al: : Prefrontal neurons and the genetics of schizophrenia. Biol. Psychiatry 50, 825-844 (2001).

- Valuable information on genetics and cognitive impairment in schizophrenia.

9. Abi-Dargham A, Mawlawi O, Lombardo I et al.: Prefrontal dopamine D1 receptors and working memory in schizophrenia. J. Neurosci. 22, 3708-3719 (2002).

10. Castner SA, Williams GV, Goldman-Rakic PS: Reversal of antipsychotic-induced working memory deficits by short-term dopamine D1 receptor stimulation. Science 287, 2020-2022 (2000).

11. Emamian ES, Karayiorgou M, Gogos JA: Decreased phosphorylation of NMDA receptor Type 1 at serine 879 in brains of patients with schizophrenia. J. Neurosci. 24, 1561-1564 (2004).

12. Meltzer HY, Matsubara S, Lee JC: The ratios of serotonin 2 and dopamine 2 affinities differentiate atypical and typical antipsychotic drugs. Psychopharmacol. Bull. 25, 390-2 (1989).

- Provides important information on the basis of first-generation atypical antipsychotic drugs (APDs).

13. Janssen PA, Niemegeers CJ, Awouters F, Schellekens KH, Megens AA, Meert TF: Pharmacology of risperidone (R 64 766), a new antipsychotic with serotonin-S2 and dopamine-D2 antagonistic properties. J. Pharmacol. Exp.Ther. 244 (2), 685-93 (1988).

14. Moore NA, Tye NC, Axton MS, Risius FC: The behavioral pharmacology of olanzapine, a novel 'atypical' antipsychotic agent. J. Pharmacol. Exp.Ther. 262 (2), 545-551 (1992).

15. Wadenberg ML, Salmi P, Jimenez P, Svensson TH, Ahlenius S: Enhancement of antipsychotic-like properties of the dopamine $\mathrm{D}_{2}$ receptor antagonist raclopride by the additional treatment with the $5-\mathrm{HT}_{2}$ receptor blocking agent ritanserin in the rat. Eur. Neuropsychopharmacol. 6, 305-310 (1996).

16. Wadenberg ML, Hicks PB, Richter TJ, Young KA: Enhancement of antipsychoticlike properties of raclopride in rats using the selective 5-HT2A receptor antagonist MDL 100,907. Biol. Psychiatry. 44, 508-515 (1998).

17. Wadenberg ML: Antagonism by 8-OHDPAT, but not ritanserin, of catalepsy produced by raclopride or SCH 23390 in the rat. J. Neural Transm. 89, 49-59 (1992).

18. Wadenberg ML, Soliman A, VanderSpek SC, Kapur S: Dopamine D2 receptor occupancy is a common mechanism underlying animal models of antipsychotics and their clinical effects. Neuropsychopharmacology 25, 633-641 (2001).

19. Andersson JL, Nomikos GG, Marcus M, Hertel P, Mathé JM, Svensson TH: Ritanserin potentiates the stimulatory effects of raclopride on neuronal activity and dopamine release selectively in the mesolimbic dopaminergic system. Naunyn Schmiedeberg's Arch. Pharmacol. 352, 374-385 (1995).

20. Newcomer JW: Second-generation (atypical) antipsychotics and metabolic effects: a comprehensive literature review. CNS Drugs 19 (Suppl. 1), 1-93 (2005).

-• Excellent review on the metabolic issues in atypical APDs.
21. Wirshing DA, Wirshing WC, Kysar L et al: Novel antipsychotics: Comparison of weight gain liabilities. J. Clin.Psychiat. 60, 358-363 (1999).

22. Newman-Tancredi A, Assié MB, Leduc N, Ormiere AM, Danty N, Cosi Cr: Novel antipsychotics activate recombinant human and native rat serotonin 5-HT1A receptors: affinity, efficacy and potential implications for treatment of schizophrenia. Int. J. Neuropsychopharmacol. 8, 341-356 (2005).

- Excellent article containing conprehensive information on the significance of the 5 -

$\mathrm{HT}_{1 \mathrm{~A}}$ receptor in schizophrenia treatment.

23. Millan MJ, Gobert A, Newman-Tancredi A et al: $S 16924((+)-2-(1-[2-(2,3-$

dihydrobanzo[1,4] dioxin-5-yloxy)-ethyl]pyrrolidin-3yl)-1-(4-fluoro-

phenyl)ethanone), a novel, potential antipsychotic with marked serotonin 5HT1A agonist properties. I. Receptorial and neurochemical profile in comparison with clozapine and haloperidol. J. Pharmacol. Exp. Ther. 286, 1341-1355 (1998).

24. Invernizzi RW, Cervo L, Samanin R: 8hydroxy-2-(di-n-propylamino)-tetralin, a selective serotonin ${ }_{1 \mathrm{~A}}$ agonist, blocks haloperidol-induced catalepsy by an action of raphe nuclei medianus and dorsalis. Neuropharmacology 27, 515-518 (1988).

25. McMillen BA, Scott SM, Davanzo E: Reversal of neuroleptic-induced catalepsy by novel aryl-piperazine anxiolytic drugs. J. Pharmacol. 40, 885-887 (1988).

26. Wadenberg ML, Ahlenius S: Antipsychotic-like profile of combined treatment with raclopride and $8-\mathrm{OH}-$ DPAT in the rat: Enhancement of antipsychotic-like effects without catalepsy. J. Neural Transm. 83, 43-53 (1991).

27. Burnet PWJ, Eastwood SL, Harrison PJ: $\left({ }^{3} \mathrm{H}\right)$ WAY100,635 for 5-HT1A receptor autoradiography in human brain: a comparison with $\left({ }^{3} \mathrm{H}\right) 8-\mathrm{OH}-\mathrm{DPAT}$ and demonstration of increased binding in the frontal cortex in schizophrenia. Neurochem. Internat. 30, 565-574 (1997).

28. Goff DC, Midha KK, Brotman AW, McCormick S, Waites M, Amico ET: An open trial of buspirone added to neuroleptics in schizophrenic patients. J. Clin. Psychopharmacol. 11, 193-197 (1991).

29. Sumiyoshi T, Matsui M, Nohara $S$ et al.: Enhancement of cognitive performance in schizophrenia by addition of tandspirone to neuroleptic treatement. Am. J. Psychiat. 158, 1722-1725 (2001). 
30. Assié MB, Cosi C, Koek W: 5- $\mathrm{HT}_{1 \mathrm{~A}}$ receptor agonist properties of the antipsychotic nemonapride: comparison with bromerguride and clozapine. Eur. J. Pharmacol. 334, 141-147 (1997).

31. Newman-Tancredi A, Gavaudan S, Conte C et al: : Agonist and antagonist actions of antipsychotic agents at serotonin 5-HT1A receptors: a $\left.{ }^{35} S\right) \mathrm{GTP} \psi \mathrm{S}$ binding study. Eur. J. Pharmacol. 355, 245-256 (1998).

32. Seeger TF, Seymour PA, Schmidt AW et al:: Ziprasidone (CP-88,059): a new antipsychotic with combined dopamine and serotonin receptor antagonist activity. J. Pharmacol. Exp.Ther. 275, 101-113 (1995).

33. Shapiro DA, Renock S, Arrington E et al: Aripiprazole, a novel atypical antipsychotic drug with a unique and robust pharmacology. Neuropsychopharmacology 28, 1400-1411 (2003).

34. Sprouse JS, Reynolds LS, Braselton JP, Rollema H, Zorn SH: Comparison of the novel antipsychotic ziprasidone with clozapine and olanzapine: inhibition of dorsal raphe cell firing and the role of $5-\mathrm{HT}_{1 \mathrm{~A}}$ receptor activation. Neuropsychopharmacology 21(5), 622-631 (1999).

35. Malhotra AK, Burdick KE, Razi K, Bates JA, Sanders M, Kane JM: Ziprasidone-induced cognitie enhancement in schizophrenia: Specificity or pseudospecificity? Schizophr. Res. PMI 16820282 87(1-3), 181-184 (2006) (Epub ahead of print).

36. Meltzer HY, Arato M, O'Connor R: Path analysis of the ZEUS study provides evidence of a direct effect of ziprasidone on primary negative symptoms in chronic, stable schizophrenia. Schizophr. Res. 41(1), 208-209 (2000).

37. Olie JP, Spina E, Murray S, Yang R: Ziprasidone and amisulpiride effectively treat negative symptoms of schizophrenia: results of a 12-week, double-blind study. Int. Clin.Psychopharmacol. 21 (3), 143-151 (2006).

38. Breier A, Berg PH, Thakore JH et al: Olanzapine versus ziprasidone: results of a 28-week double-blind study in patients with schizophrenia. Am. J. Psychiat. 162 (10), 1879-1887 (2005).

39. Zimbroff DL, Allen MH, Battaglia J et al:: Best clinical practice with ziprasidone IM: update after 2 years of experience. CNS. Spectr. 10 (9), 1-15 (2005).

40. Daniel DG, Zimbroff DL, Potkin SG, Reeves KR, Harrigan EP, Lakshminarayanan M: Ziprasidone $80 \mathrm{mg} /$ day and $160 \mathrm{mg} /$ day in the acute exacerbation of schizophrenia and schizoaffective disorder: a 6-week placebocontrolled trial. Ziprasidone Study Group.
Neuropsychopharmacology 20 (5), 491-505 (1999).

41. Swainston Harrison T, Perry CM: Aripiprazole: a review of its use in schizophrenia and schizoaffective disorder. Drugs 64 (15), 1715-1736 (2004).

42. Kane JM, Carson WH, Saha AR et al:: Efficacy and safety of aripiprazole and haloperidol versus placebo in patients with schizophrenia and schizoaffective disorder. J. Clin. Psychiat. 63 (9), 763-771 (2002).

43. Langlois X, Frans A, Megens A et al:: Pharmacology of aripiprazole in rats: $\mathrm{A}$ comparison with the classical neuroleptic haloperidol. Int. J. Neuropsychopharmacol. 9 (Suppl. 1), S220 (2006).

44. Bolonna AA, Kerwin RW: Partial agonism and schizophrenia. Br. J. Psychiat. 186, 7-10 (2005).

-• Excellent review on the concept of partial agonism.

45. Elsworth JD, Roth RH: Dopamine autoreceptor pharmacology and function. In: I: Dopamine Receptors. Neve RL (Ed.). Humana Press, Totowa, NJ, USA, 232-265 (1997).

46. Clark D, Hjorth S, Carlsson A: Dopamine-receptor agonists: mechanisms underlying autoreceptor selectivity. I. Review of the evidence. J. Neural Transm. 62, 1-52 (1985).

47. Ohmori T, Koyama T, Inoue $T$, Matzubara S, Yamashita I: B-HT920, a dopamine $\mathrm{D} 2$ agonist, in the treatment of negative symptoms of chronic schizophrenia. Biol. Psychiatry 33, 687-693 (1993).

48. Wetzel H, Hillert A, Grunder G, Benkert O: Roxindole, a dopamine autoreceptor agonist, in the treatment of positive and negative schizophrenic symptoms. Am. J. Psychiat. 151, 1499-1502 (1994).

49. van Vliet BJ, Ronken E, Tulp M, Feenstra R, Kruse CG, Long SK: DU 127090: A highly potent, atypical dopamine receptor ligand - High potency but low efficacy at dopamine D2 receptors in vitro. Eur. Neuropsychopharmacol. 10(Suppl. 3), S293 (2000).

50. Feenstra RW, De Moes J, Hofma JJ et al: New 1-aryl-4-(biarylmethylene)piperazines as potential atypical antipsychotics sharing dopamine D2 receptor and serotonin 5HT1A receptor affinities. Bioorg. Med. Chem. Letters 11, 2345-2349 (2001).

51. Marquis KL, Hertel P, Reindeers JH, van der Neut M, Ronken E, Hesselink MB: Bifeprunox: a novel atypical antipsychotic sharing dopamine $\mathrm{d} 2$ receptor partial agonism and serotonin $5-\mathrm{HT}_{1 \mathrm{~A}}$ receptor agonism. Schizophr. Bull. 31, 305 (2005).

52. Long SK, Feenstra R, Kruse CG, van Vliet BJ: DU 127090: A highly potent, atypical dopamine receptor ligand - Partial agonist character in neurochemistry assays in vivo. Eur. Neuropsychopharmacol. 10 (Suppl. 3), S295 (2000).

53. Cosi C, Carilla-Durand E, Assié MB et al:: Partial agonist properties of the antipsychotics SSR 181507, aripiprazole and bifeprunox at dopamine D2 receptors: $\mathrm{G}$ protein activation and prolactin release. Eur. J. Pharmacol. 535, 135-144 (2006).

54. Bruins Slot LA, De Vries L, Newman-Tancredi A, Cussac D: Differential profile of antipstchotics at serotonin 5-HT1A and dopamine $\mathrm{D}_{2 S}$ receptors coupled to extracellular signal-regulated kinase. Eur. J. Pharmacol. 534, 63-70 (2006).

55. Assié MB, Ravailhe V, Faucillon V, NewmanTancredi A: Contrasting contribution of 5hydroxytryptamine $1 \mathrm{~A}$ receptor activation to neurochemical profile of novel antipsychotics: Frontocortical dopamine and hippocampal serotonin release in rat brain. J. Pharmacol. Exp.Ther. 315(1), 265-272 (2005).

56. Haddjeri N, Dahan L, Mnie-Filali O, Arnt J, Hertel P: Effects of bifeprunox on the rat ventral tegmental area dopamine and dorsal raphe serotonin neuronal activity. Int. J. Neuropsychopharmacol. 9 (Suppl. 1), S219 (2006).

57. Cussac D, Heusler P, Martel, NewmanTancredi A: The new antipsychotics, bifeprunox, F15063 and SLV313, behave as partial agonists at dopamine D4 receptors: comparison with typical and atypical antipsychotics. Soc. Neurosci. Abstr. 332.4 (2006).

58. Hertel P, Olsen CK, Didriksen M et al:: Bifeprunox: providing a new option for treating psychosis. Eur. Neuropsychopharmacol. 15 (S3), S486 (2005a).

59. McCreary A: Bifeprunox: A unique, atypical antipsychotic. Eur. Psychiat. 20, S67 (2005).

60. Arnt J, Hesselink MB, Didriksen M, van der Heyden JA, Feenstra RW, Kruse CG: DU127090: A novel partial dopamine agonist with antipsychotic activity, a putative potent full spectrum antipsychotic with low EPS potential. Schizophr. Res. 60(N1,S), 104 (2003).

61. Hertel P, Brennum LT, Helboe L et al:: Bifeprunox: Relationship between antipsychotic potential, EPS liability and dopamine $\mathrm{D} 2$ receptor occupancy in rats. Neuropsychopharmacol. 30 (Suppl. 1), 256 (2005b). 
62. Hesselink MB, McCreary AC, Glennon JC et al: Bifeprunox: a novel partial agonist for the $\mathrm{D} 2$ receptor with antagonistic capabilities depending on the dopaminergic tone. Eur. Neuropsychopharmacol. 15 (S3), S486 (2005).

63. Hesselink MB, McCreary AC, Ronken E, Feenstra RW, van Kolfschoten A, van Scharrenburg G: DU127090, SLV308 and SLV318: Characterization of a chemically related class of partial dopamine agonists with varying degrees of 5-HT1A agonism. Eur. J. Neurol. 10 (Suppl. 1), S167 (2003).

64. van Kolfschoten A, Hesselink MB, Long SK et al:: DU127090: A novel partial dopamine agonist with antipsychotic activity partial agonist character in functional assays in vivo. Schizophr. Res. 60(N1 S), 117 (2003).

65. Casey DE, van Vliet BJ, Feenstra RW, Kruse CG, Long SK: DU127090: A highly potent, atypical dopamine receptor ligand Behavioral effects of DU 127090 in Cebus non-human primates. Eur. Neuropsychopharmacol. 10(Suppl. 3), S333 (2000).

66. Bardin L, Kleven MS, Barret-Grévoz C, Depoortère R, Newman-Tancredi A: Antipsychotic-like vs cataleptogenic actions in mice of novel antipsychotics having D2 antagonist and 5-HT1A agonist properties. Neuropsychopharmacol 31(9), 1869-1879 (2006).

67. Kleven MS, Barret-Grévoz C, Bruins-Slot L, Newman-Tancredi A: Novel antipsychotic agents with 5-HT1A agonist properties: Role of 5-HT1A receptor activation in attenuation of catalepsy induction in rats. Neuropharmacology 49, 135-143 (2005).

68. Auclair A, Kleven MS, Besnard J, Depoortère R, Newman-Tancredi A: Actions of novel antipsychotic agents on apomorphine-induced PPI disruption: Influence of combined serotonin 5-HT1A receptor activation and dopamine D2 receptor blockade. Neuropsychopharmacol. 31(9), 1900-1909 (2006).

69. Bruins-Slot L, Kleven MS,

Newman-Tancredi A: Effects of novel antipsychotics with mixed D2 antagonist/5HT1A agonist properties on PCP-induced social interaction deficits in the rat. Neuropharmacology 49, 996-1006 (2005).

70. Bardin L, Malfetes N, Newman-Tancredi A, Depoortere R: Phencyclidine-induced deficits in working and reference memories using a food retrieval task in a holeboard apparatus in rats: effects of new generation antipsychotics with mixed D2 and 5-HT1A properties. Soc. Neurosci. Abstr. 666.19 (2006).

71. Hertel P, Husum H, Marquis K, Herremans AHJ, Hesselink MB: Bifeprunox: a novel atypical antipsychotic with in vivo 5-HT1A receptor agonistic activity. Schizophr. Res. 81(Suppl. 1), 83 (2006).

72. Putman M, Katuin G, Hjort Christensen L, Pratt G: Challenges in determining the protein binding of two in all aspects very different analytes in one plasma sample: bifeprunox and valproate. Presented at: FABIAN Symposium. Organon, OSS, The Netherlands (2005).

73. de Vries MH, de Haes JU, Long SK et al: DU 127090: A highly potent, atypical dopamine receptor ligand - Pilot study of dopamine D2 receptor occupancy after multiple oral administration of DU 127090 to healthy male volunteers, using ${ }^{11} \mathrm{C}$ raclopride by means of positron emission tomography. Eur. Neuropsychopharmacol. 10(Suppl. 3), S293 (2000).

74. de Vries MH, de Haes JU, Grahnén A et al: DU 127090: a novel partial dopamine agonist with antipsychotic activity. Pilot study of dopamine D2 receptor occupancy after multiple oral administration of DU 127090 to healthy male volunteers, using ${ }^{11} \mathrm{C}$-raclopride by means of positron emission tomography. Schizophr. Res. 60(N1,S), 239-240 (2003).

75. de Vries MH, Grahnén A, Nyman L et al: Bifeprunox: Dopamine D2 receptor occupancy. Biol. Psychiatry 60, (2006) (In Press).

76. Rapaport M, Barbato LM, Heisterberg J, Yeung PP, Shapira NA: Efficacy and safety of bifeprunox versus placebo in the treatment of patients with acute exacerbations of schizophrenia. Presented at: ACNP Meeting. Hollywood, FL, USA, December 3-7 (2006).

77. Casey D, Barbato LM, Heisterberg J, Yeung PP, Shapira NA: Efficacy and safety of bifeprunox in the treatment of patients with acute exacerbations of schizophrenia: Results of a dose-finding study. Presented at: ACNP Meeting. Hollywood, FL, USA, December 3-7 (2006).

78. Barbato LM, Potkin SG, Heisterberg J, Yeung PP, Shapira NA: A randomized, double-blind, placebo-controlled study of bifeprunox, a partial dopamine $\mathrm{D} 2$ receptor agonist, in patients with acute exacerbations of schizophrenia. Presented at: ACNP Meeting. Hollywood, FL, USA, December 3-7 (2006).

79. Bourin M, Debelle M, Heisterberg J et al.: Long-term efficacy and safety of bifeprunox in patients with schizophrenia: A 6-month, placebo-controlled study. Presented at: ACNP Meeting. Hollywood, FL, USA, December 3-7 (2006).

80. Shapiro NA, Newcomer JW, Barbato LM, Heisterberg J, Yeung PP: The metabolic profile of bifeprunox in the treatment of patients with schizophrenia. Presented at: ACNP Meeting. Hollywood, FL, USA, December 3-7 (2006).

81. Wolf W: DU-127090 Solvay/Lundbeck. Curr. Opin. Investig. Drugs 4 (1), 72-76 (2003).

Earlier review on bifeprunox.

82. Johnston LC, McCreary AC, Rose S, Smith L, Jackson M, Jenner P: Association between intrinsic activity and the antiparkinsonian effect of a novel dopamine D2 agonist series in the 1-methyl-4-phenyl1,2,3,6-tetrahydropyridine treated primate model of Parkinson's disease. Eur. J. Neurol. 10 (Suppl. 1), S169 (2003).

\section{Websites}

101. Schizophrenia information www.schizophrenia.com/sznews/archives/cat _schizophrenia_medications.html

102. US National Institutes of Health -

\section{Clinical Trials}

www.ClinicalTrials.gov

103. Ziprasidone product summary www.en.wikipedia.org/wiki/Ziprasidone

104. Drug development www.drugdevelopment-technology.com

105. Solvay/Lundbeck $A / S$ press releases www.lundbeck.com/investor/releases/ default.asp

\section{Affiliation}

- Marie-Louise G Wadenberg University of Kalmar, Department of Natural Sciences, Norra Vagen 49, SE-391 82 Kalmar, Sweden

Tel.: +46480446277;

Fax: +46480446244

marie-louise.wadenberg@hik.se 